\title{
Correction to: Handling Complex Meta-analytic Data Structures Using Robust Variance Estimates: a Tutorial in $\mathbf{R}$
}

\author{
Emily E. Tanner-Smith ${ }^{1}$ Elizabeth Tipton ${ }^{2} \cdot$ Joshua R. Polanin $^{3}$ \\ Published online: 14 November 2019 \\ (C) Springer Nature Switzerland AG 2019
}

\section{Correction to: J Dev Life Course Criminology (2016) 2:85-112 https://doi.org/10.1007/s40865-016-0026-5}

The original publication of this article contained the wrong image in Figure 1. The correct Figure 1 is presented at the next page.

The online version of the original article can be found at https://doi.org/10.1007/s40865-016-0026-5

Emily E. Tanner-Smith etanners@uoregon.edu

1 University of Oregon, 5251 University of Oregon, Eugene, OR 97403, USA

2 Teachers College, Columbia University, 525 W 120th Street, Box 118, New York, NY 10027, USA

3 American Institutes for Research, 1000 Thomas Jefferson Street, NW, Washington, DC 20007, USA 


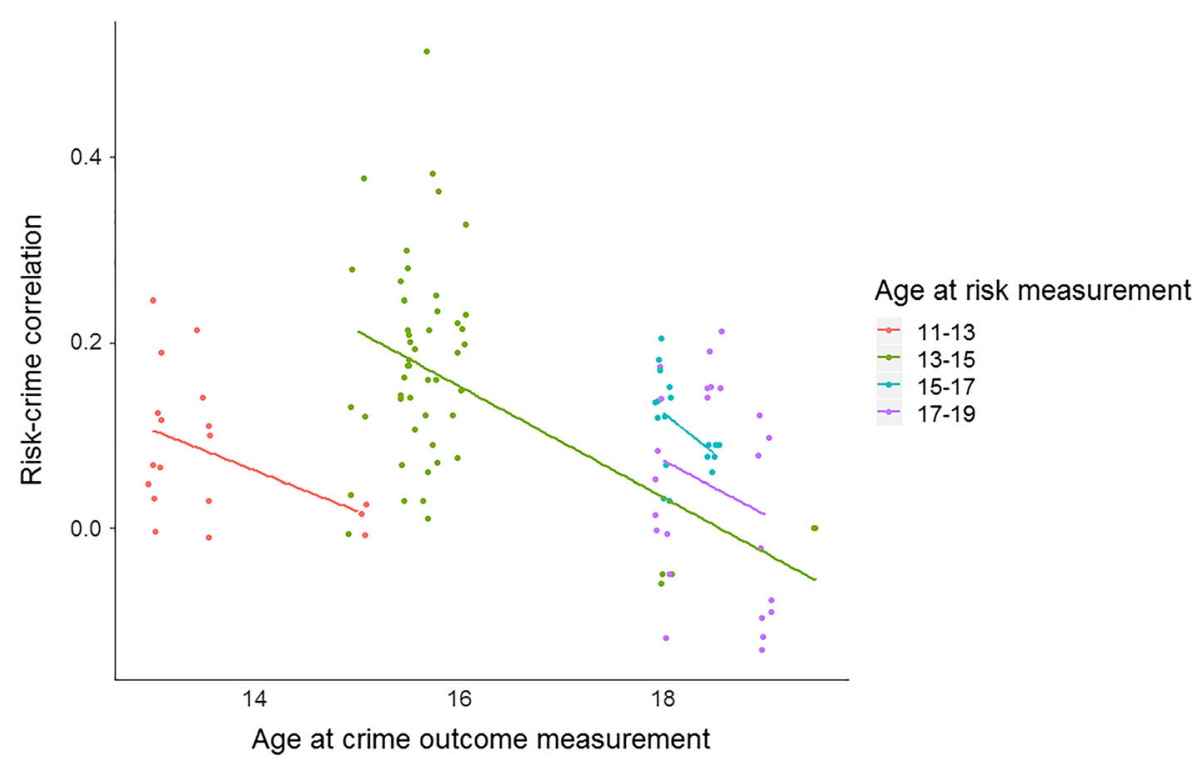

